Discussion Paper No. 17-027

The European Electronic

\title{
Communications Code:
}

\section{A Critical Appraisal with a Focus on} Incentivizing Investment in Next Generation Broadband Networks

Wolfgang Briglauer, Carlo Cambini, Thomas Fetzer, and Kai Hüschelrath

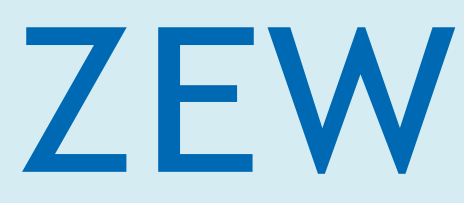

Zentrum für Europäische Wirtschaftsforschung $\mathrm{GmbH}$ Centre for European Economic Research 
Discussion Paper No. 17-027

\section{The European Electronic Communications Code: A Critical Appraisal with a Focus on Incentivizing Investment in Next Generation Broadband Networks}

Wolfgang Briglauer, Carlo Cambini, Thomas Fetzer, and Kai Hüschelrath

Download this ZEW Discussion Paper from our ftp server:

http://ftp.zew.de/pub/zew-docs/dp/dp17027.pdf

Die Discussion Papers dienen einer möglichst schnellen Verbreitung von neueren Forschungsarbeiten des ZEW. Die Beiträge liegen in alleiniger Verantwortung der Autoren und stellen nicht notwendigerweise die Meinung des ZEW dar.

Discussion Papers are intended to make results of ZEW research promptly available to other economists in order to encourage discussion and suggestions for revisions. The authors are solely responsible for the contents which do not necessarily represent the opinion of the ZEW. 


\title{
THE EUROPEAN ELECTRONIC COMMUNICATIONS CODE: A CRITICAL APPRAISAL WiTH A FOCUS ON INCENTIVIZING INVESTMENT IN NEXT GENERATION BROADBAND NETWORKS
}

\author{
Wolfgang Briglauer*, Carlo Cambini ${ }^{\dagger}$, Thomas Fetzer ${ }^{\circ}$ and Kai Hüschelrath*
}

June 2017

\begin{abstract}
In September 2016, the European Commission (EC) published its proposal for a directive establishing the European Electronic Communications Code (EECC) - with one key aim being the provision of sufficient incentives for infrastructure investments into high-speed communication networks. Based on a detailed review of the theoretical and empirical literature of the most relevant regulatory measures - that is, co-investment models as well as different types of access regulation - we provide a critical appraisal of the respective provisions in the EECC. We find that, although the EECC can generally be seen as step into the right direction, the expected effects on investment incentives as well as substantial implementation challenges in combination with a high degree of complexity of the envisaged measures contain substantial potential for improvement.
\end{abstract}

\section{JEL Class}

L96, L51

\section{Keywords}

Telecoms' Review, Regulatory Framework, European Union, Investment, Infrastructure, Next Generation Networks, Broadband, Access Regulation, Co-Investment

* ZEW Centre for European Economic Research and MaCCI Mannheim Centre for Competition and Innovation, P.O. Box 1034 43, D-68034 Mannheim, Germany, E-mail: briglauer@zew.de. Corresponding author. Briglauer and Cambini (2017) are the authors of a study entitled "The Role of Regulation in Incentivizing Investment in New Communications Infrastructure" which was financially supported by Deutsche Telekom AG, Bonn, Germany. The present paper builds in parts on this study but represents independent research and the opinions of the authors only.

+ Politecnico of Torino, Corso Duca degli Abruzzi, 24, 10129 Torino, Italy. Florence School of Regulation European University Institute, E-mail: carlo.cambini@polito.it.

University of Mannheim and MaCCI Mannheim Centre for Competition and Innovation, Schloss Westflügel, D-68161 Mannheim, Germany, E-mail: fetzer@jura.uni-mannheim.de.

* ZEW Centre for European Economic Research and MaCCI Mannheim Centre for Competition and Innovation, Address: P.O. Box 1034 43, D-68034 Mannheim, Germany; University of Mannheim, L7, 3-5, 68131 Mannheim, Germany, E-mail: hueschelrath@zew.de. 
One of the most important aspects of the EU regulatory framework for electronic communications is the regulation of broadband access infrastructures - which form the basis for the entire digital economy and are therefore of particular technical and economic importance. In recent years, in a time of increasing digitalization, operators of first-generation broadband networks have been facing the need to upgrade their networks due to an overwhelming increase in demand for bandwidth and real time criteria. 'Next Generation Access' (NGA) broadband networks based on fiber-optic technology enable a massive increase in bandwidth capacity and the adoption of completely new services and applications on the demand side. Given sufficient availability and adoption, many consider this to be a promising way to increase long-term productivity and prosperity.

One fundamental goal of the European Commission (EC) and national regulatory authorities (NRAs) therefore is to accelerate the deployment of innovative and high-performance broadband infrastructures. However, given the high levels of investment that a comprehensive NGA deployment requires, providing sufficient investment incentives remain essential. Furthermore, if we take into account all the market developments to date related to actual NGA coverage and adoption patterns in most EU member states (European Commission, 2016a), it cannot be assumed that the existing market and competition conditions will result in broad-scale coverage - including rural areas - with NGA infrastructures and high take-up of NGA services in the foreseeable future. Assuming that NGA deployment indeed goes hand in hand with substantial welfare gains, the question thus arises as to which regulatory policies enhance (or diminish) investment incentives.

In its Digital Agenda for Europe (DAE) ${ }^{1}$ - in combination with recently announced plans for an European Gigabit Society ${ }^{2}$ - the EC not only fortifies its belief in the strategic importance of broadband infrastructures and services for economic development, but especially set ambitious coverage and adoption goals. In working towards the envisaged goals, the EC first and foremost aims at strengthening the incentives of private companies to invest in both the deployment of high-capacity broadband infrastructures and to enhance adoption on the demand side through the design and implementation of appropriate regulatory frameworks. In line with the visions developed in its DAE and Gigabit Society targets, in September 2016, the EC published a detailed proposal for a directive establishing the European Electronic Communications Code (European Commission, 2016b), which will substantially revise the existing regulatory framework for communications markets (hereinafter referred to as 'EECC'). With the directive, the EC is pursuing three core objectives: (1) equal baseline conditions for all market participants, (2) uniform application of the legal regulations and (3) the provision of sufficient incentives for investment in high-capacity NGA networks. ${ }^{3}$

See https://ec.europa.eu/digital-agenda/en (last accessed on 22 June 2017) for further information.

2 See https://ec.europa.eu/digital-single-market/en/connectivity-european-gigabit-society (last accessed on 22 June 2017) for further information.

3 The EECC refers to 'very high capacity networks' which are defined as follows (Art. 2 (2)): "[V]ery high capacity network means an electronic communications network which either consists wholly of optical fiber 
In this context, we aim at providing a critical appraisal of the EECC with a particular focus on the expected impacts of the proposed regulatory measures on the incentives to invest in highcapacity NGA networks, i.e. the third core objective. ${ }^{4}$ Although there already exist numerous theoretical and empirical contributions that address the relationship between investment and regulation - both in general and with respect to electronic communications markets - the topic gains new significance in the context of the current review of the EU regulatory framework. Accordingly, our aim is to provide a critical appraisal of the EECC's envisaged measures to enhance infrastructure investment against the background of the existing academic literature and relevant structural characteristics and developments in broadband markets. In reviewing the academic literature we will only focus on the most relevant and recent contributions from both theoretical and empirical perspectives. For comprehensive surveys, the reader is referred to Balmer (2013) who reviews the literature focusing on geographic (de-) regulation and cooperative NGA investment as well as Briglauer et al. (2015) who provide an overview of the existing academic literature on the impact of old and new broadband infrastructure access regulation on NGA investment and adoption of new broadband services. HSBC (2016) represents a policy-oriented review of a broad range of regulatory measures foreseen in the EECC proposal from an institutional investor's point of view.

The remainder of the paper is structured as follows. Sections 2 and 3 provide an assessment of the role of relevant regulatory schemes in incentivizing infrastructure investment. While Section 2 concentrates on the relevance of co-investments models, Section 3 focuses on the role of access regulation (subdivided further into asymmetric 'significant market power' (SMP) access regulation and symmetric non-SMP access regulation). In both sections, we first introduce into the respective regulatory concepts followed by detailed reviews of the most related theoretical and/or empirical research and finally making use of the gained insights as part of our critical assessment of the measures envisaged in the EECC. Section 4 concludes the paper with a summary of the main insights from economic research as well as the derived implications for amendments of the EECC.

elements at least up to the distribution point at the serving location or which is capable of delivering under usual peak-time conditions similar network performance in terms of available down- and uplink bandwidth, resilience, error-related parameters, and latency and its variation." Although the EECC does not explicitly refer to certain NGA technologies as being particularly desirable - and explicitly emphasizes the importance of technological neutrality (Art. 3 (3) lit c, recital 24) - it remains unclear whether the term 'very-high capacity networks' used on several occasions in the EECC (e.g. recital 13 and Art. 2 (2)) only refers to Fiber to the home (FTTH) and Fiber to the building (FTTB) networks in a narrower sense. In this paper we apply a broader definition and refer to all high-speed wireline deployment scenarios including hybrid-fiber or 'second-life copper/coax' technologies as NGA scenarios.

4 Please note that we will limit our analysis to fixed (or wireline) communications networks, although mobile (or wireless) networks and mobile broadband services are playing an increasingly important competitive role. In particular, the 4th generation (4G) mobile communications technology already offers bandwidths that are increasingly comparable with some NGA network architectures and the importance of mobile broadband may even increase with the deployment of $5 \mathrm{G}$ technologies. Yet, we focus on wireline broadband only as access and co-investment remedies are expected to be imposed on wireline NGA infrastructures only. 


\section{The role of co-investment models}

Competition intensity in electronic communications markets may vary significantly across regions. In competitive ('black') areas, there is no need for sector-specific ex ante access regulations on the basis of the essential facility doctrine or the concept of market dominance. In 'white' areas, where network deployment would not be profitable even for a monopolist, it is not possible to incentivize network deployment through sector-specific access regulation; public policies based on subsidies would be a considerably more effective instrument in these circumstances.

In 'grey' areas, where only one infrastructure provider is active, it is much more difficult to determine the best policy as a range of trade-offs must be taken into account. In grey (or otherwise white) areas, co-operation (or: co-investment) models appear as an effective measure, in principle, for sharing risks related to future demand and market exposure as well as capital formation in case of capital market imperfections (Nett and Stumpf, 2011) and thus for generating additional investment incentives. Investment sharing might also come hand in hand with cost reductions, e.g., in case of traditional and non-traditional telecommunications operators due to the sharing of skills, capabilities and different infrastructure elements in the network hierarchy (see, e.g., ITU, 2015). Co-investment could also ensure that inefficient investment - such as the unnecessary duplication of infrastructures - can be avoided (see Briglauer et al., 2015). However, it is important to note that the reasons why co-investment agreements might be successful do not imply that market risk disappears altogether with such agreements. Risk and uncertainty clearly remain; the existence of a co-investment agreement simply shares the exposure to these risks to all investors that commit to invest ex ante (i.e., before the investment is made), but it clearly affects the decision to invest.

Support for co-investment models in the form of market-driven collaboration solutions has already been mentioned in the EC's NGA recommendation (European Commission, 2010, recitals 12, 15, 19, 27 and Art. 13, 16) and in its framework directive (European Commission, 2002, Art. 8 (5) lit d), wherein co-investment and other risk-sharing models are explicitly intended as a means of supporting investment. Co-investment models with 'open-access' are based on the commitment of an infrastructure provider subject to the regulatory constraint that interested parties are offered access on a non-discriminatory basis. From the angles of both risk-sharing (framework directive, Art. 8 (5) d)) and the primacy of voluntary market solutions (framework directive, Art. 8 (5) f)), NGA co-investment models correspond well with the current European regulatory framework.

Co-investment agreements can involve several operators investing jointly in different infrastructure components ('co-build', based on joint ventures if applicable) and then giving each other (or third parties) access as well as different versions of volume-discount models with only one firm deploying the infrastructure. In 'volume-discount co-investment' models, competitors must book and pay for a specific quota in advance - thus taking a share of the demand risk - in order to secure a lower monthly payment compared to basic access products (typically based on a fixed fee upfront payment). 
When comparing network sharing in mobile and fixed networks, the question arises as to why co-investment occurs relatively infrequently in fixed networks (see ITU, 2015, pp. 6-8). ${ }^{5}$ One reason could be that such co-investment activities - geographic sharing in particular, but also co-investment in general - might interfere with competition law and therefore might lead to substantial fine impositions (particularly as sharing agreements not only involve physical infrastructure elements but inevitably also include the sharing of commercial information among co-investing parties). Such concerns appear to be more serious in fixed networks where there is typically already less competition than in oligopolistic mobile markets. Ex ante access conditions imposed on the dominant co-investing operator represent another obstacle which is not present in the case of mobile-network sharing. Finally, co-ordination costs in fixed networks might be higher due to comparatively higher heterogeneity in terms of business models, network elements and size distribution of involved operators (see ITU, 2015, pp. 9-10).

\subsection{Literature review on co-investment: Theory and experimental evidence ${ }^{6}$}

Cost and/or risk-sharing rules can be viewed as a relevant alternative instrument to standard access price regulation, potentially enhancing dynamic efficiency by expanding NGA coverage, consumer surplus and social welfare. Nitsche and Wiethaus (2011) analyse a twostage framework with identical firms, where the incumbent is the only firm entitled with an investment option and investment success in terms of future demand is uncertain. Their work compares the impact of different modes of regulation (cost-based access, co-investment ${ }^{7}$ and regulatory holiday) in terms of investment and consumer welfare outcomes, and conclude that co-investment can be particularly beneficial both in terms of investment incentives and consumer welfare.

Cambini and Silvestri $(2012,2013)$ use a similar model to Nitsche and Wiethaus (2011), but analyse a dynamic framework with vertically differentiated firms looking also to social, and not only consumer, welfare. In particular, Cambini and Silvestri (2013) study two different approaches of co-investment compensation mechanisms: basic investment sharing, where the firms share the investment cost and do not pay each other any compensation for the use of the NGA networks; joint-venture, where the firms share the investment cost and then set an internal access charge for the use of the NGA infrastructure that maximises their joint profits. These papers show that risk-sharing does indeed lead to higher welfare in comparison to

5 Whereas the term 'network sharing' typically applies to co-operation models in the mobile industry, the term 'co-investment' is typically used with respect to co-investing fixed network operators.

6 Please note that - due to the absence of econometric research on co-investment in communication markets we review the main results of the only paper (we are aware of) that also contains some experimental evidence at the end of this section.

7 The authors assume that the co-investment option (risk sharing in their terminology) is treated in a reduced form in which parties share the fixed cost of investment through some agreement and then they can use the NGN network without further side payments. Inderst and Peitz (2012b), instead, analyze cost-sharing agreements between an incumbent firm and an entrant, in the form of long term contracts concluded before the investment is made, as opposed to contracting taking place after the network has been constructed. The authors show that the former type of agreement reduces the duplication of investment and may lead to more areas being covered. Coordination at the investment level may come at a price, though, which is reduced competition in the areas covered. 
alternative modes of regulation, such as partial regulation (ex ante intervention applies only to the legacy network, while the NGA network is left unregulated) or full regulation (where access to NGA networks is also regulated), especially in the presence of demand uncertainty. In particular, Cambini and Silvestri (2013) show that basic investment sharing leads to higher welfare as it ensures more competition than joint-venture and fairly high investment incentives. Joint-venture gives relatively higher investment incentives, but it carries more risks in terms of anticompetitive effects of the investment cooperation agreements potentially leading to a higher risk of foreclosure.

All the above-mentioned papers, however, compare different levels of investment under different regulatory scenarios, but they do not really capture the role of co-investment in expanding NGA deployment taking into account the difference in investment costs across different areas of a country. A model that instead considers this aspect is Bourreau et al. (2016), in which the authors focus on co-investment as an alternative regulatory obligation to standard access regimes aiming at spurring market competition and investment incentives. With co-investment an entrant can request access to an incumbent's infrastructure by sharing the investment cost of the infrastructure after an investment plan has been announced by the incumbent. In this context, the first question that the authors address is whether co-investment can stimulate infrastructure investments and enhance social welfare in comparison to a standard access pricing regime. They thus compare different regulatory regimes in terms of infrastructure coverage and social welfare. The second relevant question addressed in Bourreau et al. (2016) is the role of demand uncertainty, relating particularly to the fact that demand levels are difficult to predict in the planning and construction stages of new infrastructures. The presence of such demand uncertainty implies that a firm must invest before final demand is known, while an access seeker can wait until enough information is available to decide whether to enter. Thus, access provides entrants with a cream-skimming option that is exercised exactly when market outcomes are good, whereas the network investor bears all the downside risks. In this context, the authors study how demand uncertainty affects the relative effectiveness of co-investment agreements (as part of which commitments must be made before uncertainty is resolved).

The model builds on Bourreau et al. (2012) who assume a country composed of a continuum of areas that differ with respect to the fixed cost of rolling out the new infrastructure (i.e., from high-density-low-investment cost areas to low-density-high-investment costs areas). In this country, an incumbent firm rolls out a new infrastructure and an entrant can decide where and how to enter in all different areas. The model compares three different regulatory regimes considered, i.e. i) pure access only, ii) pure co-investment, or iii) co-investment with access. The 'pure access' regime corresponds to the standard ('service-based') access regime, i.e., the entrant can ask for access in all the areas where the incumbent has deployed its network; it then pays a linear access tariff set by the regulator. In the 'pure co-investment' regime, the entrant can ask the incumbent to share its infrastructure in covered areas by taking on half of the investment cost; however, access is not available outside the areas covered with fiber. Finally, the 'co-investment with access' regime allows the entrant to decide whether to ask for access or to co-invest in each covered area. 
The incumbent and the entrant then compete at the retail level in every area where they both operate. ${ }^{8}$ The degree of competition may vary according to the kind of regulatory regime in question. In the 'pure access' regime, duopoly competition emerges only in those areas where the entrant decides to enter and ask for access; under the 'pure co-investment' regime, duopoly competition emerges in all areas in which the two firms co-invest, while - given the absence of access obligations - in those areas where only the incumbent invests, the incumbent has a monopoly position. Finally, under the 'co-investment with access' regime, the entrant can choose in which areas to co-invest while in the rest of the country - where only the incumbent invests - the entrant can ask for access and compete with the incumbent.

The implementation of a standard wholesale access obligation on new infrastructures involves the classic trade-off between static efficiency and investment in coverage. The authors find that compared to the pure access regime, the pure co-investment regime leads to, first, more intense competition in the areas where the firms operate a shared network and to, second, larger coverage. On the downside, it involves a monopoly area where retail prices are higher (but a large part of this region would not be covered at all under the access regime). Adding an access obligation on top of co-investment ('co-investment with access') reduces the incumbent's profit in marginal areas; thus total coverage is lower in this regime than under pure co-investment. In addition, co-investment coverage is also lower. This is because the access option offered to the entrant constitutes an opportunity cost of co-investment, reducing co-investment incentives compared to the pure co-investment regime. In terms of social welfare, results show that if the access price is low, social welfare is higher in case no access is granted, because a low access charge reduces both the incentive for the entrant to co-invest and the incumbent's incentive to cover costly areas.

The role of demand uncertainty largely affects the equilibrium coverage. In the face of demand uncertainty, the entrant can wait for the true state of demand to become apparent before asking for access. Hence, the entrant has the option to wait while the incumbent has to invest before demand is apparent and thus anticipating the entire risk. In this scenario, the authors show that the entrant has reduced investment incentives and larger uncertainty leads to lower total coverage. The pure co-investment regime involves a pre-commitment and does not suffer from this problem, and would therefore appear to be the preferred regulatory regime not only in terms of investment incentive, but also from a social perspective.

From a policy perspective, Bourreau et al. (2016) consider a general model of co-investment that is valid whatever kind of co-investment agreement can be implemented. This also implies that the organizational mode of the co-investment agreements is not important but rather the impact that they have on extending NGA coverage. In turn, it also implies that the decision on the kind of agreement can be left to the market in order to reduce the administrative burdens on co-investors. From a competition policy point of view, a second interesting insight can be derived from the model. NRAs often push for imposing open co-investment agreements aiming at giving later entrants the chance to enter the co-investment agreement. Although not directly addressed by the authors, the above results could easily be applied; i.e., granting late

8 This assumption makes the paper different from other studies that specifically look at the 'collusive' effect of a co-investment agreement (see, e.g., Inderst and Peitz, 2013; Krämer and Vogelsang, 2016). 
entrants the possibility to 'wait and see' whether market demand expands - and only committing to invest when this eventually happens - invites cream-skimming behavior. This, in turn, reduces or even eliminates the investment incentives for early investors who have to bear the entire risk and uncertainty.

Another competition policy issue related to co-investment is the risk of collusion. Krämer and Vogelsang (2016) performed a laboratory experiment to study the effect of co-operation in broadband markets, with an underlying model where non-cooperation would be the optimal choice for the individual. They find that co-operation still arises due to communication between players, and that this facilitates collusion while not stimulating further investment. Although it remains an open question whether this increased chance of collusion materializes in actual markets, it is also important to mention that for at least some of the countries in which co-investment models played a role - such as France, Spain, Switzerland or Portugal (Balmer, 2013, p. 31) - a higher network coverage has been observed.

In any case, it is important to close with the reminder that different regulatory models can have different impacts on the risk of collusion: a 'pure co-investment' agreement without access in monopolistic areas may lead to higher probabilities of collusion compared to the 'co-investment with access' agreement. Indeed, in areas where access is available, firms are more likely to compete and this reduces the risk of collusion between the same firms in the co-invested areas. Therefore, adding collusion into the framework may rebalance the benefits of co-investment without access (though negatively affecting NGA coverage).

\subsection{EECC: Intended measures and critical appraisal}

The EECC in Art. 74 envisages an exemption from access regulation for new network elements with very high capacity, insofar as the following conditions are met on a cumulative basis (Art. 74 (1)): "i) the deployment of the new network elements is open to co-investment offers according to a transparent process and on terms which favor sustainable competition in the long term including inter alia fair, reasonable and non-discriminatory terms offered to potential co-investors; flexibility in terms of the value and timing of the commitment provided by each co-investor; possibility to increase such commitment in the future; reciprocal rights awarded by the co-investors after the deployment of the co-invested infrastructure; ii) the deployment of the new network elements contributes significantly to the deployment of very high capacity networks; iii) access seekers not participating in the co-investment can benefit from the same quality, speed, conditions and end-user reach as was available before the deployment, either through commercial agreements based on fair and reasonable terms or by means of regulated access maintained or adapted by the national regulatory authority."

On the one hand, the EECC's proposed exemption from regulation is tied to several additional conditions which are further laid out in Annex IV. In Annex IV lit. a, the EECC pushes for imposing open co-investment agreements on the SMP operator which enables access for later entrants to join the co-investment agreement. Furthermore, the co-investment agreements must also comprise the ability to leave a co-investment arrangement and sell it to a third party (Annex IV lit. c). In some sense, letting the co-investment agreement remain open over its entire period of validity on a non-discriminatory basis is in accordance with standard 
wholesale access regulation and its associated investment incentives (Sections 3.3-3.4). The content and procedures involved in the package must also be transparent for all market participants and the package must safeguard sustainable competition for the long term (Annex IV lit. b). The EECC also provides for a dynamic adjustment of access prices reflecting the timing of commitments made at later stages (Annex IV lit. c). However, imposing such open co-investment specifications not only increase regulatory uncertainties and transaction costs but also further reduce the incentives to co-invest because it negatively affects the incentives to pre-commit on investment. The option for late entrants to pay an access fee that includes a fraction of those risks would work if, and only if, the regulator is able to precisely assess those risks and monetize them through the access fee - apparently an extremely complex and difficult endeavour to implement in theory, let alone in regulatory practice.

Consequently, co-investment subject to ex ante approval still represents a rather strong regulatory component - with the result that co-investment models differ substantially from purely voluntary market solutions. As shown in the theoretical literature, allowing the coinvestment agreement to always remain open with some pre-defined access conditions is equivalent to the 'access option' in the model and their associated ex ante investment incentives. In contrast, in order to enhance market-based solutions, co-investment models should not face certain a priori restrictions with respect to the organizational design of how firms co-operate. Furthermore, the risk of imposing investment-diminishing access regulations is of particular concern in view of the aforementioned co-investment obstacles that already prevail in fixed-network industries; i.e., to induce co-investment these regulatory obstacles should be minimized.

On the other hand, the inherent concept of ensuring that all involved parties effectively share risk should be viewed positively due to its investment-encouraging effect. However, coinvestment models will only induce additional infrastructure investment if the regulatory conditions - imposed ex ante on co-investing parties - are not too restrictive in terms of accruing future investment rewards and in relation to the actual extent of risk-/cost-sharing. The sharing effect most likely increases, first, the longer participating parties have to cooperate, second, the more commercially negotiated terms prevail and, third, the lower the scope of regulatory gaming. In case (an) infrastructure operator(s) reach(es) a commercially negotiated long-term agreement with other market participants, NRAs might even consider a full withdraw from ex ante regulations / side conditions together with a switch to ex post market monitoring (subject to other competition factors inside and outside the market, see HSBC, 2016, p. 29).

\section{The role of access regulation}

The questions as to what extent existing broadband wholesale access regulations hamper or encourage investment in new networks and what influence they have on both end-consumer 
prices and quality of services has been the subject of debate for years. ${ }^{9}$ At the European level, regulated infrastructure providers argue that mandatory access obligations with regulated fees would diminish incentives to invest in the deployment and improvement of access infrastructure. By contrast, many NRAs and alternative (service-based) providers believe that the deployment of new broadband infrastructures also contains the risk of new and potentially more pronounced monopoly areas and therefore requires appropriate ex ante access regulation. In Sections 3.1 and 3.2 we briefly introduce into the two main types of access regulation, ${ }^{10}$ i.e. asymmetric SMP access regulation and symmetric non-SMP access regulation, respectively. We then provide a detailed review of the related theoretical and empirical literature in Sections 3.3 and 3.4, respectively. Section 3.5 assesses the EECC's investment incentives in view of the envisaged regulatory access policies.

\subsection{Asymmetric SMP access regulation}

Already the EC's 2002 regulatory framework ('second package') was founded largely on the concept that firms with SMP underlie certain restrictions and obligations ex ante and that contrary to competition law - no evidence of an actual abuse of this market power is required for these restrictions and obligations to apply (see especially Art. 14 to 16 of the framework directive, European Commission, 2002). ${ }^{11}$ According to these articles, NRAs have to carry out market analysis procedures at regular intervals that comprise a three-stage market analysis sequence.

The first stage involves based on the so-called 'three-criteria-test' 12 a definition of relevant communications markets that could be subject to sector-specific regulation. In the second stage, NRAs then investigate whether there is effective competition in these markets and/or whether (at least) one firm in these markets has SMP. The European regulatory framework (framework directive Art. 14 (1)-(2)) basically differentiates between two possibilities to constitute significant market power (SMP): 'Single dominance' and 'joint dominance'. In case SMP is detected, in the third stage, NRAs impose sector-specific ex-ante obligations on

9 The reader is referred to Telecommunications Policy special issue published in 2013 (Volume 37(10)) which collects controversial papers on the topic "Regulatory approaches and investment in new communications infrastructure".

10 As indicated in Section 2, co-investment models represent another form of access regulation in case of mandatory obligations (such as non-discrimination or open access requirements) that have to be fulfilled ex ante.

11 The 'Telecoms Package', adopted in 2002 and amended in 2009 includes the following specific directives aiming at establishing a harmonized framework for the regulation of electronic communications networks: i) directive 2002/21/EC or 'framework directive'; ii) directive 2002/20/EC or 'authorization directive'; iii) directive 2002/19/EC or 'access directive'; iv) directive 2002/22/EC or 'universal service directive'; v) directive 2002/58/EC or 'directive on privacy and electronic communications'. The EECC integrates sectorspecific regulations that were previously divided across separate directives and combines them into one directive (with only data protection regulations still treated separately as part of the ePrivacy directive).

12 According to this test the following criteria have to be met cumulatively to justify ex ante regulation (Art. 65 EECC): "(a) high and non-transitory structural, legal or regulatory barriers to entry are present; (b) there is a market structure which does not tend towards effective competition within the relevant time horizon, having regard to the state of infrastructure-based competition and other sources of competition behind the barriers to entry; (c) competition law alone is insufficient to adequately address the identified market failure(s). 
the dominant undertaking in accordance with the specific competition problems identified in the relevant market. Accompanying forms of regulation at wholesale level would then need to be imposed in a way that could ensure adequate correspondence with (current or potential) competition problems at the end-user level. Ex-ante regulation has to be taken into consideration up to the point at which self-sustaining competition is sufficiently established at the end-user level in the relevant markets. As a matter of fact NRAs have done so but one of the important clarifications of the new framework is that wholesale regulation should be removed if there is no competition problem in the retail market.

Regulatory instruments at the wholesale level are generally always to be viewed in the form of 'access prices' and 'access products'. The previous broadband wholesale obligations implemented in the European regulatory framework were primarily: i) full local loop unbundling (LLU), ii) shared access, iii) bitstream and iv) DSL-Resale. With regard to the investment ladder, all the access products reflect the basic relation that access seekers have to make bigger investments if they also want to obtain more options in terms of shaping the quality of retail products. It was only when the full unbundling model was introduced that alternative competitors were able to also technically differentiate products at end-consumer level. The ideal type of interaction and dynamics for these instruments has been popularized in the EU as the 'ladder of investment' hypothesis. ${ }^{13}$ This process should ultimately help provide competition in the field of local loop networks that is sustainable because it would be based on access infrastructures. The latter is thus the highest rung on the investment ladder and the first that would enable complete exemption from asymmetrically imposed access obligations (with some complementary symmetric obligations such as 'duct access' in place). It is against this background that Bauer (2010, p. 69) cites the ladder principle alongside the essential facility doctrine ${ }^{14}$ as a core justification for the imposition of asymmetric access obligations (for the same reasoning see also Renda, 2016, p. 8-9).

Figure 1 shows the actual development in broadband wholesale access products in the EU member states between 2005 and 2015. It is clear that service-based competition has only become well established under full unbundling; according to Figure 1, 'LLU access' accounts for more than $78 \%$ of all DSL connections based on access regulations in 2015 . The rise in

13 This approach was initially developed by Cave et al. (2001), Cave and Vogelsang (2003) for the EC and later modified in Cave (2006). In the US, the approach is known as the 'stepping-stone hypothesis' and was introduced as part of the 1996 Telecommunications Act.

14 The underlying essential facilities doctrine has its origins in US law and in principle applies to markets exhibiting natural monopoly characteristics, which give rise to monopolistic behavior such as refusal to deal. The specific conditions of an essential facility were laid out in the case MCI Communications Co v. AT\&T (708 F.2d 1081) in 1982. According to this decision, to establish obligatory access to an essential facility there must be i) a control of the facility by a monopolist; ii) economic inability to reasonably replicate the facility iii) feasibility to supply the facility to alternative operators. Under EC law the essential facilities doctrine has been based on Art. 82 (Art. 102) of the EC Treaty (TFEU) which prohibits the abuse of market dominance. The doctrine has since become part of the EU regulatory framework (European Commission, 2002a, recital (6) and Art. 12). Moreover, when applying the essential facility doctrine of Art. 102, the absence of replicability is not enough on its own to make the provision of access mandatory. The European Court of Justice (ECJ) further requires that refusal of access is likely to eliminate all competition in the downstream market and that the refusal to grant access cannot be objectively justified (ECJ, November 26, 1998, case No. C-7/97, Report of Cases I 7791 - Bronner). 
unbundling saw a simultaneous drop in other access variants. This can be seen as partial confirmation of the ladder principle and there is also corresponding evidence for this in the academic literature (see Bacache et al., 2014). However, it is equally clear that the last rung of the ladder, which represents infrastructure competition in the local loop and the long-term goal of the ladder of investment approach (see Renda, 2016, p. 21), could not be realized nationwide on the basis of access regulations. ${ }^{15}$ Referencing the specific market structure for local loops and the underlying 'economies of density', Vogelsang points out that the investment ladder has been unsuccessful in ultimately delivering infrastructure-based competition within a timeframe of more than a decade as a "natural outcome of the economics of fixed broadband access" (Vogelsang, 2013, p. 212). Another reason for the failure of the ladder of investment hypothesis in inducing infrastructure-based competition is the fact that it was never implemented by NRAs as initially suggested by Cave and Vogelsang. The authors made the very important point that NRAs must be able and willing to 'burn down' the lower rungs of the ladder over time to induce further investment on the part of entrant firms seeking access. NRAs, however, have appeared to be reluctant to eliminate existing access regulations over the course of liberalization and have instead established a complex system of multiple access regulations, which gave rise to strong regulatory dependencies instead of infrastructure-based independence. ${ }^{16}$

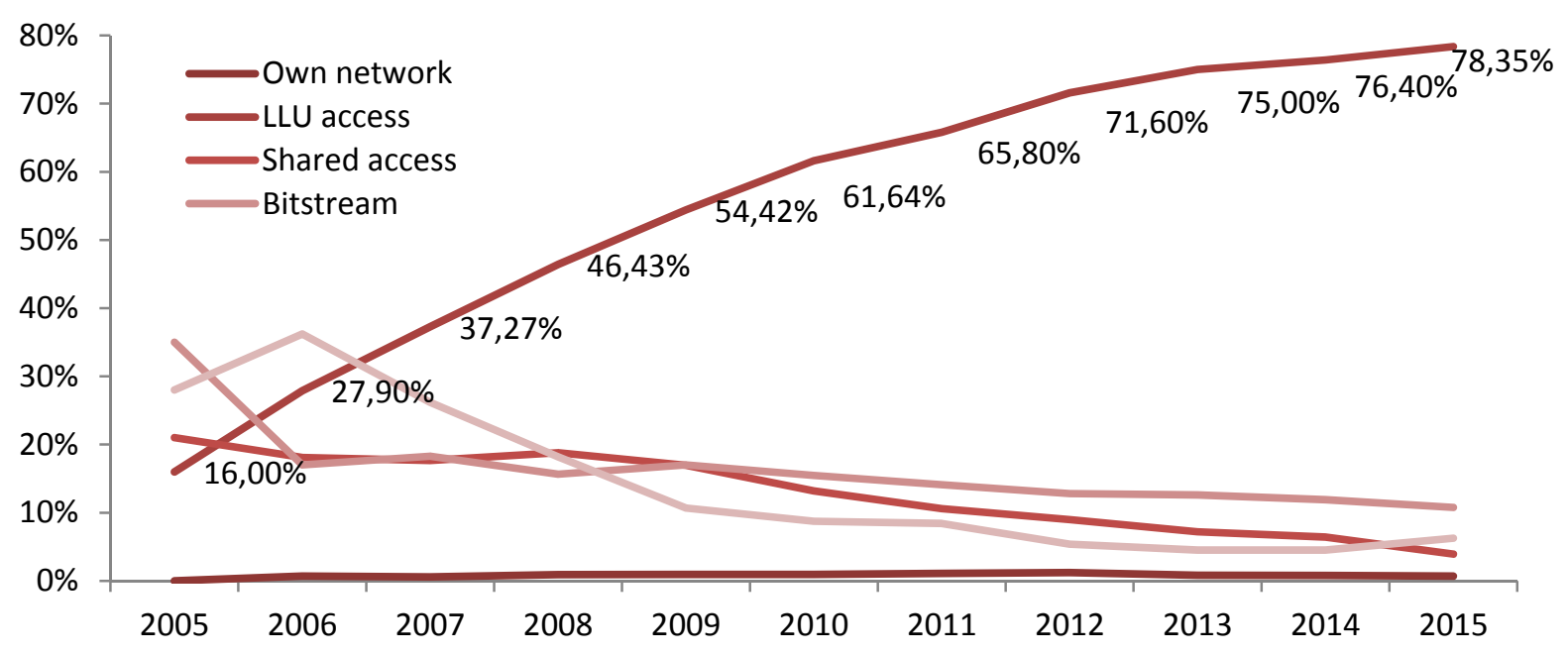

Figure 1: Relevance (\%) of old broadband access in the $E U^{17}$

15 A few notable exceptions are e.g.: NetCologne (Germany), Iliad (France) or Optimus/Sonaecom (Portugal), where former service-based operators started to deploy their own FTTH/B access infrastructure (Godlovitch et al. 2015a, p. 21; company information on NetCologne (see https://www.netcologne.de/ueberuns/unternehmen/geschichte). In a recent report, Cave and Feasey (2017, p. 22) conclude accordingly: "Investors in new FTTH networks have sometimes been existing providers of broadband services using DSL technology, but not often." Typically, the aforementioned cases are heavily focused on high ARPU business consumers in urban areas.

16 For a critical discussion of the ladder of investment and its underlying assumptions the reader is referred to Bourreau et al. (2010).

17 Data represents EU averages and is gathered from the EC's Digital Agenda Scoreboard (see https://ec.europa.eu/digital-single-market/en/digital-scoreboard). 
These empirical findings on the ladder of investment hypothesis can also be applied directly to the migration to NGA infrastructures and second-life copper/coax migration technologies, since these will exhibit even greater economies of density. This is to be expected because the relevant distribution points in the access network are closer to the end-consumer. This is why profitable replicability in the case of the aforementioned hybrid NGA networks declines further and why regulatory forms of access can indeed deliver service-based competition, but are unlikely to result in infrastructure-based competition. In fact, the main alternative NGA infrastructure operators already had cost advantages in the form of their physical infrastructure elements, which were not established as the result of any inducement from sector-specific regulation: "Besides incumbents, only firms with prior access investments (either in other networks, such as cable TV, or in ducts, such as municipal electric utilities) have successfully invested in such networks" (Vogelsang, 2013, p. 212). In most cases these alternative networks represent high-end FTTH/B network deployments without any reliance on asymmetrically regulated access products in conjunction with a pre-existing customer base but rather with opportunities to exploit various economies of scope (Cave and Feasey, 2017, p. 21;29).

In addition, the most broadly established form of access regulation in the past - full physical unbundling - encounters substantial implementation problems when it comes to migration to NGA networks; and thus its importance as a central wholesale product will be limited and at a lower rung of the new ladder representing versions of 'virtual unbundled access'. Furthermore, there is also a risk in the migration process that access regulation will become more complex due to the old investment ladder, path dependence and access products that need to be redefined: „[A] regulatory transition to deregulation entails propensities to micromanage the process to generate preferred outcomes, visible competitors, and expedient price reductions" (Hausmann and Taylor, 2013, p. 206). Thus, besides the additional costs of regulation, there would be additional uncertainty over the types of regulation to be implemented in the future. Nonetheless, the EC adopted the ladder principle into its 'NGA recommendation' as a guiding principle: "The appropriate array of remedies imposed by an NRA should reflect a proportionate application of the ladder of investment principle" (European Commission, 2010a, recital (3)).

In accordance with the above discussion, any remaining asymmetric access regulations serve as a mechanism for safeguarding competition as an ultima ratio in otherwise non-competitive (white or grey) areas but not for inducing self-sustainable infrastructure-based competition.

\subsection{Symmetric non-SMP access regulation}

Besides voluntary forms of co-investment, the joint usage of infrastructures can also take shape based on mandatory symmetrical access obligations. In contrast to asymmetric regulation, symmetric forms of regulation concern measures that must be imposed on all providers, irrespective of the presence of market power. However, the essential facility doctrine is a common starting point for both forms of regulation (see Nett and Stumpf, 2011, p. 8-9). In this context, general examples of symmetric obligations for all network operators would include rights of joint installation and shared use in the case of physical network infrastructure elements that are essential to NGA deployment. According to Art. 12 (1)-(2) 
framework directive, NRAs may impose co-location and facility sharing on all firms: "Where an undertaking providing electronic communications networks has the right under national legislation to install facilities on, over or under public or private property, or may take advantage of a procedure for the expropriation or use of property, national regulatory authorities shall encourage the sharing of such facilities or property. ... Such sharing or coordination arrangements may include rules for apportioning the costs of facility or property sharing." In short, not only wireline and wireless infrastructures are covered by the regulation but also infrastructures not owned by telecommunications companies, such as routes used by power supply networks, pylons and existing cable duct capacities, as well as empty conduits and overhead power cables on traffic routes (Nett and Stumpf, 2011, p. 7).

Insofar as symmetrical obligations are suitable for delivering synergy potentials and lowering total investment costs - such as the comparatively high installation costs in Europe where underground deployment is the norm - they will increase the profitability of NGA projects and, ceteris paribus, overall investment activity. Accordingly, in its cost reduction directive, the EC envisages shared use obligations on a large scale for public communications network operators and firms that own rights of use, primarily due to cost aspects (European Commission, 2014b, recital 13): "It can be significantly more efficient for electronic communications network operators, in particular new entrants, to re-use existing physical infrastructures, including those of other utilities, in order to roll out electronic communications networks, in particular in areas where no suitable electronic communications network is available or where it may not be economically feasible to build up a new physical infrastructure. Moreover, synergies across sectors may significantly reduce the need for civil works due to the deployment of electronic communications networks and therefore also the social and environmental costs linked to them, such as pollution, nuisances and traffic congestion. Therefore this Directive should apply not only to public communications network providers but to any owner or holder of rights to use, in the latter case without prejudice to any third party's property rights, extensive and ubiquitous physical infrastructures suitable to host electronic communications network elements, such as physical networks for the provision of electricity, gas, water and sewage and drainage systems, heating and transport services."

It is important to note, however, that in order to increase investment, symmetric regulations must not ultimately result in extending asymmetric access regulations to a variety of infrastructure elements and all infrastructure operators regardless of actual market power (SMP). This would run contrary to, first, deregulation steps that have already been put in place and, second, the central goal of promoting investment. Accordingly, mandatory nonSMP access obligations imposed on 'passive' infrastructure elements ${ }^{18}$ must not discourage ex ante investment incentives while clearly lowering deployment costs due to synergies. However, assuming that costs are reasonably distributed between operators, that opportunity costs for the infrastructure owners are factored in, and that proportionality is strictly observed,

18 While the passive infrastructure relates to physical infrastructure elements such as trenches, poles, ducts and optical fiber, optical distribution frames, patch panels etc., the active elements relate "to the electronic network equipment needed to bring the passive infrastructure alive, as well as the operational support systems required to commercialize the fiber connectivity" (FTTH Council Europe, 2012, pp. 18-19). 
shared use and joint installation obligations - when appropriately combined with voluntary forms of co-investment - should offer considerable potential for reducing total deployment costs. In this case, symmetric regulatory measures would also be suitable for boosting the deployment of optical fiber networks both in terms of geographical spread and investmentintensive FTTH/B deployments.

\subsection{Literature review on access regulation: Theory}

First NGA-specific papers - particularly the seminal contribution by Bourreau et al. (2012) assume that entrants use the copper network managed by the incumbent to compete on basic broadband services and eventually invest in fiber infrastructure, at least in parts of a country. However, they do not consider the case in which the entrant is a cable operator that does not need access to the existing copper infrastructure to provide broadband services. Additionally, they also do not consider the case in which only the fixed telecom incumbent is subject to ex ante regulation while the cable operators - investing in fiber or in updating their access technology - are not subject to any ex ante restrictions. This latter case implies the presence of an asymmetric regulation that has characterized the previous and current EU regulatory frameworks as described in Section 3.1. These features are important for fine-tuning the theory to apply to actual regulatory and market conditions - considering that in most European countries the main category of entrants in NGA markets are indeed cable-TV operators using an alternative legacy infrastructure to the incumbent's copper access infrastructure.

In a recent paper by Briglauer et al. (2017), the authors develop a model of investment competition in fiber deployment that extends the existing literature (most notably Bourreau et al., 2012) in multiple ways. The aim of these extensions is to account for a number of stylized facts about the European NGA infrastructure investment patterns and regulatory approaches and to derive hypotheses that can subsequently be taken to the data. Most importantly, they account for heterogeneous entrants to the NGA market, which are present in many European markets. In particular, they consider the presence of three (rather than two) different competitors: an incumbent telecom firm that owns a legacy copper-based telephone network; a cable firm that owns a legacy cable-TV network (and does not have to access the existing copper network to provide its final services); and a service-based entrant that does not own any legacy infrastructure. The first two firms provide broadband services using their respective legacy networks; the third relies on mandated access to the incumbent firm's legacy network. However, only the telecom incumbent is regulated ex ante on both the copper and fiber infrastructures; i.e., the model thus explicitly considers the effect of an asymmetric SMP regulation regime imposed on old and new access infrastructures. In sum, this implies that the impact of LLU prices on the incentive to invest is not limited to the incumbent and telecombased entrants but also applies to cable operators who could benefit indirectly from copperbased access regulation through the degree of market competition.

This framework was then extended to account for the presence of NGA regulation and the impact of cost asymmetry on investment. The results show that, when the incumbent is expected to be the leader in NGA investment, the presence of ex ante regulation imposed on fiber access infrastructure lowers the incumbent firm's incentive to expand NGA coverage. 
This result complements the one in Bourreau et al. (2014), who also highlight the detrimental effect of fiber regulation on the incentive to invest. This happens because introducing regulation on fiber networks limits the incumbent's options to exploit revenues from its investment and this in turn decreases the incentive to invest. However, when a cable firm is the leader, the decision to invest in fiber is not at all affected by the presence of fiber access regulation. Similarly, Vogelsang (2016) also finds that NGA regulation either should not be imposed or it should be 'soft' in order to incorporate the additional risk of investment and to avoid mitigating investment incentives for entrants and incumbents. More generally, the author states that new services should not be regulated at all; however, if such a solution is not feasible, a regulatory holiday regime, i.e., regulation is delayed until a set of necessary requirements have been met, should be considered as a further option.

In sum, the results in Briglauer et al. (2017) show that the role of the fiber access regulation on active elements on investment incentives is unambiguously relevant. A less stringent form of fiber access regulation (i.e., a higher access price or lack of regulation for active elements) incentivizes all firms to invest more in NGA networks. This is also true for cable firms in all cases. However, when cable firms are the investment leader, their incentive to invest is unaffected by access regulation. Thus, a less stringent form of fiber access regulation (i.e., a higher access price or lack of regulation) incentivizes the cable firm to invest more only when it is a follower in NGA deployment and therefore must invest in order to compete with the incumbent; otherwise, when cable operators are the leader in fiber deployment, strict fiber regulation has no effect on a cable operator's investment decision and is only detrimental to the incumbent. In a nutshell, results show that soft regulation of fiber access - or even lifting regulatory obligations temporarily or entirely - has an overall positive effect on market investment of all operators.

Additionally, the model by Briglauer et al. (2017) not only points out that NGA regulation, if severe, is detrimental to fiber investment, but, on top of this negative effect, the implementation of a regime of asymmetric regulation between incumbents and cable operators would only have further distortionary effects by favoring the latter over the former. Hence, from a policy perspective, the model suggests that, if the NRA wants to impose NGA regulation, this regulation should be symmetric and involve all firms investing in NGA, not only the incumbent ones. However, this conclusion does not imply that the imposition of symmetric access remedies, i.e., the extension of SMP remedies to all investing companies, is the best solution. Indeed, the theoretical results previously described (see Bourreau et al., 2012 and 2014; Inderst and Peitz, 2012a and 2012b; Vogelsang, 2016) all show that too strict regulation of fiber access negatively affects aggregate (i.e., market level) investment and hence leads to a reduction in total fiber deployment. From a policy perspective, this implies that - in case some degree of regulation should be imposed - regulatory interventions should be symmetric and limited to passive and not active elements of the fiber network in order to partially mitigate the adverse effect of extensive ex ante interventions in fiber deployment.

The significance of a symmetric regulation is also emphasized when actual differences in investment costs are taken into consideration. Indeed, reports (see e.g. Taga et al., 2009; Cave and Feasey, 2017, p. 36) show that the investment costs for cable operators to upgrade their 
access infrastructures are much lower than the investment costs for fiber upgrades faced by incumbent operators. In this scenario, Briglauer et al. (2017) show that the cost advantage for cable operators increases their probability of becoming the leader in the new market in terms of NGA deployment: the larger this difference in cost, the lower the probability that a telecom incumbent will become a leading investor in fiber. Consequently, in the face of investment cost asymmetries, the implementation of asymmetric NGA access regulation that affects only the 'second mover' (i.e., incumbents) not only has a vicious effect on incumbent firms by depriving their incentives to invest in fiber, but also unbalances the playing field in favor of the unregulated cable operators and thus perpetuates existing regulatory-induced market asymmetries. Obviously, a symmetric regime would level market competition; however, at the expense of a reduction in total NGA investment.

\subsection{Literature review on access regulation: Empirics}

Due to the virtual absence of empirical research on symmetric access regulation, we limit our subsequent literature review to the case of asymmetric access regulations. In this context, Table 1 summarizes the findings as well as the data employed in the literature. The empirical literature on the impact of broadband access regulations can be divided into two broad categories: i) quantitative analyses focusing on the regulatory impact on NGA investment and ii) quantitative analyses focusing on the impact on NGA adoption. Due to data availability constraints several of the empirical studies refer to measures of adoption. Adoption can be a proxy for investment and, at the same time, might provide a better proxy for consumer welfare in efficiently functioning markets.

From the empirical literature, we can infer that all studies that use data from European countries find a negative impact of ex ante access regulations or related service-based competition on NGA deployment in terms of investment or adoption. Only one study that uses OECD and ITU data for NGA adoption finds insignificant results (Samanta et al., 2012). Whereas all these studies use aggregate country level data, one study makes use of Japanese data (Minamihashi, 2012) at the municipal level and also finds that unbundling regulations have a negative impact on entrants' incentive to invest in NGA infrastructure (while leaving the incumbents' investment unaffected). A recent study by Bourreau et al. (2017) employs panel data for French municipalities. The authors find a positive impact of the presence of unbundling operators on entry of NGA operators. Whereas the authors employ a rich data set with more than 36.000 observations they do not employ a direct measure of regulation or service-based competition. In line with the majority of the other studies they also find a positive impact of cable infrastructure and a negative impact of the incumbent's upgraded legacy infrastructure (replacement effect).

Overall, as the empirical literature indicates a negative impact of ex ante access regulations on NGA investment and NGA adoption, deregulatory approaches are supported - a conclusion that appears to be largely in line with the older broadband-related literature as surveyed in Cambini and Jiang (2009) and the subsequent empirical analysis on regulation and broadband investment. ${ }^{19}$ Although there are only few NGA related empirical contributions available, the

19 See, inter alia, Bouckaert et al. (2010), Grajek and Röller (2012) or Crandall et al. (2013). 
studies reviewed in Table 1 suggest that the main findings of the older broadband-related literature are apparently even more applicable to NGA infrastructures.

Interestingly these findings are confirmed not only by independent assessments of financial market analysts but also by the EC itself in the form of showing first signs to acknowledge that strict cost-based access regulation is at odds with the goal of promoting investment in new infrastructures. In this respect, particular reference to the EC's recommendation for standardized non-discrimination obligations (European Commission, 2013a) must be made. In terms of the stipulations in European Commission (2013a), efficiency-oriented NRAs would fully deregulate NGA and legacy infrastructure in black areas and apply legacy regulation with comparatively high prices plus NGA regulation with only softer regulation obligations in grey areas. In its 2014 market recommendation, the EC further expresses concerns about negative effects of regulation on investment (European Commission, 2014a, explanatory note): "Regulation must be targeted and balanced in a way that addresses the true obstacles to effective competition in the sector: an excessive regulatory burden on operators would stifle investment and innovation." Overall, it appears that the EC increasingly adjusted its policy on regulation and investment in light of industry experience and empirical evidence. 
Table 1: Overview of empirical studies on the impact of regulation on investment ${ }^{*}$ )

\section{Author(s) Data Main results}

\begin{tabular}{|c|c|c|}
\hline $\begin{array}{l}\text { Minamih- } \\
\text { ashi } \\
(2012)\end{array}$ & $\begin{array}{l}\text { Japan } \\
2005-2009 \\
\text { Municipal } \\
\text { level }\end{array}$ & $\begin{array}{l}\text { - Unbundling regulations hinder cable entrants from investing in own } \\
\text { - IGA infrastructure } \\
\text { - Incumbents' investment are unaffected }\end{array}$ \\
\hline $\begin{array}{l}\text { Briglauer } \\
\text { et al. } \\
(2013)\end{array}$ & $\begin{array}{l}\text { EU27 } \\
\text { countries } \\
2005-2011 \\
\text { National level }\end{array}$ & $\begin{array}{l}\text { - The more effective service-based competition is, the more negative the } \\
\text { impact on NGA investment } \\
\text { - Infrastructure competition from cable and mobile networks affects NGA } \\
\text { investment non-linearly }\end{array}$ \\
\hline $\begin{array}{l}\text { Yoo } \\
(2014)\end{array}$ & $\begin{array}{l}\text { US and } \\
\text { European } \\
\text { countries } \\
2011-2012 \\
\text { National level }\end{array}$ & $\begin{array}{l}\text { - Service-based competition and NGA investment are negatively } \\
\text { correlated } \\
\text { - Infrastructure competition from cable networks is positively correlated } \\
\text { with NGA investment }\end{array}$ \\
\hline $\begin{array}{l}\text { Bacache } \\
\text { et al. } \\
(2014)\end{array}$ & $\begin{array}{l}15 \text { European } \\
\text { countries } \\
17 \text { semesters } \\
2002-2010 \\
\text { National level }\end{array}$ & $\begin{array}{l}\text { - Ladder of investment hypothesis supported at lower rungs } \\
\text { - Presence of multi-layer access regulation does not increase NGA } \\
\text { investment }\end{array}$ \\
\hline $\begin{array}{l}\text { Briglauer } \\
\text { (2015) }\end{array}$ & $\begin{array}{l}\text { EU27 } \\
\text { countries } \\
2005-2011 \\
\text { National level }\end{array}$ & $\begin{array}{l}\text { - A higher unbundling price positively impacts NGA investment and the } \\
\text { effect is stronger the more effective the unbundling regime is } \\
\text { - The more effective service-based competition is, the more negative the } \\
\text { impact on NGA investment } \\
\text { - The replacement effect from legacy infrastructure exerts a negative } \\
\text { impact on NGA investment }\end{array}$ \\
\hline $\begin{array}{l}\text { Briglauer } \\
\text { et al. } \\
(2017)\end{array}$ & $\begin{array}{l}\text { EU27 } \\
\text { countries } \\
\text { 2003-2014 } \\
\text { Firm level } \\
\end{array}$ & $\begin{array}{l}\text { - A higher unbundling price positively impacts NGA investment from } \\
\text { incumbent operators but it has no impact on cable and other operators } \\
\text { - Stronger NGA access regulations diminish NGA investment from } \\
\text { incumbent operators but it has no impact on cable and other operators }\end{array}$ \\
\hline $\begin{array}{l}\text { Bourreau } \\
\text { et al. } \\
(2017)\end{array}$ & $\begin{array}{l}\text { France } \\
\text { 2010-2014 } \\
\text { Municipal } \\
\text { level }\end{array}$ & $\begin{array}{l}\text { - Positive impact of the number of LLU operators and upgraded cable on } \\
\text { NGA investment } \\
\text { - Negative impact of VDSL }\end{array}$ \\
\hline \multicolumn{3}{|r|}{ Studies examining the impact on NGA adoption } \\
\hline $\begin{array}{l}\text { Wallsten } \\
\text { and } \\
\text { Hausladen } \\
\text { (2009) }\end{array}$ & $\begin{array}{l}\text { EU countries, } \\
\text { Japan and } \\
\text { Korea } \\
\text { 2002-2007 } \\
\text { National level }\end{array}$ & $\begin{array}{l}\text { - The more effective unbundled local loops or bitstream unbundling is, the } \\
\text { lower the rate of NGA adoption } \\
\text { - Infrastructure-based competition has a positive impact on NGA adoption }\end{array}$ \\
\hline $\begin{array}{l}\text { Samanta } \\
\text { et al. } \\
(2012)\end{array}$ & $\begin{array}{l}\text { ITU/OECD } \\
25 \text { countries } \\
1999-2009 \\
\text { National level }\end{array}$ & - Unbundling regulation has no significant impact on NGA adoption \\
\hline $\begin{array}{l}\text { Jeanjean } \\
\text { (2013) }\end{array}$ & $\begin{array}{l}15 \text { European } \\
\text { countries } \\
2007-2012 \\
\text { National level }\end{array}$ & - Tight copper access regulation decreases speed of NGA adoption \\
\hline $\begin{array}{l}\text { Briglauer } \\
\text { (2014) }\end{array}$ & $\begin{array}{l}\text { EU27 } \\
\text { countries } \\
2004-2012 \\
\text { National level }\end{array}$ & $\begin{array}{l}\text { - Wholesale broadband regulation lowers the rate of NGA adoption } \\
\text { - Infrastructure-based competition from first-generation broadband and } \\
\text { mobile networks affects NGA adoption non-linearly } \\
\text { - Network effects lead to an endogenous NGA adoption process }\end{array}$ \\
\hline $\begin{array}{l}\text { Briglauer } \\
\text { and } \\
\text { Cambini } \\
(2016)\end{array}$ & $\begin{array}{l}\text { EU25 } \\
\text { countries } \\
2003-2014 \\
\text { National level }\end{array}$ & $\begin{array}{l}\text { - An increase in the unbundling price positively effects NGA adoption; } \\
\text { effect is stronger the more effective the unbundling regime is }\end{array}$ \\
\hline
\end{tabular}

*) Table 1 constitutes a modified and updated version of the table in Briglauer et al. (2015, p. 19-20). 


\subsection{EECC: Intended measures and critical appraisal}

With regard to the residual relevance of asymmetric access regulation, the EECC envisages a logical sequence of steps (Art. 71 (1)) according to which this form of regulatory intervention - the strongest from a conceptual point of view - is only to be applied as a last resort. First, a NRA must first check whether asymmetric access to civil engineering assets is already sufficient to safeguard competition in corresponding end-consumer markets. Moreover, the NRA must consider whether there are already other possible forms of access to wholesale inputs, commercial agreements or symmetrical access obligations in place, which render the imposition of additional symmetric access obligations obsolete (Art. 71 (2)). For making this assessment the EECC refers to the distinction of so-called 'black', 'grey' and 'white' areas, which has been established by the European Commission (2013b, guidelines 61 following) in its state aid rules. In areas that are classified as 'black' from a competitive perspective and where there are at least two infrastructures in the access network, the measures pursuant to Art. 70 along with competition law ought to be adequate. In areas with three independent infrastructures, the application of competition law should be considered sufficient (recital 175). In areas with only one infrastructure NRAs must make a case-by-case assessment. For this assessment, an important factor are commercial wholesale access agreements offered by the infrastructure owner.

Limiting asymmetric wholesale regulation in this way is to be welcomed in view of the negative impact of access regulation and investment identified in the related theoretical and empirical literature. However, there remains the question of an economic justification for the differentiation between two and three infrastructures within black areas. Furthermore, Art. 70 is in parts redundant in light of comprehensive existing symmetric regulation pursuant to the cost-reduction directive (European Commission, 2014b) and Art. 70 (2) that extend asymmetric access regulations beyond the scope of Art. 71 to include infrastructure elements outside the bounds of the relevant market definition: "National regulatory authorities may impose obligations on an operator to provide access in accordance with this Article, irrespective of whether the assets that are affected by the obligation are part of the relevant market in accordance with the market analysis." Accordingly, this specification not only implies an extension of the scope of asymmetric regulation but it also runs contrary to the logical structure of the market analysis procedure under the EU regulatory framework - which aligns asymmetric access regulations to specified access products within relevant markets.

In Art. 66 (4), the EECC envisages that the NRA will have to carry out a cost-benefit analysis. This is reasonable in view of the costs related to the complexity of (new) wholesale access products and their regulation. Naturally, potential efficiency gains from imposed regulations must not be overshadowed by the additional transaction and implementation costs. Another development that is to be welcomed in terms of reducing regulatory complexity for access products is the proposed reduction of the number of access instruments (i.e., the removal of pure resale obligation as the lowest rung of the ladder) in Art. 71. In this context, it is interesting to note that the EECC does not refer to the 'ladder of investment' hypothesis any more - even though this has been considered as a guiding principle since the introduction of the 2002 regulatory framework. 
The EECC also envisages an extension of the regulation period from three years at present to five years (Art. 65 (5)). By extending the regulation period to five years, the EC hopes to increase planning certainty for regulated firms in order to increase, where possible, their willingness to invest (recital 162). Insofar as NRAs can credibly commit ex ante not to intervene during the regulatory period, extending this period should indeed increase planning capabilities on the part of infrastructure operators and might therefore increase investment incentives at the margin given that it aligns the regulatory review period more closely with the NGA investment cycle.

To achieve the investment objectives, the EECC envisages a promotion of symmetric market regulation - which does not take account of SMP - in order to reduce deployment costs and costs due to parallel administrative procedures for obtaining rights of way and thus ultimately promote investment incentives. Art. 44 of the EECC provides rights of way regulation which can be interpreted as a kind of symmetric regulation imposed on co-location and sharing of network elements and associated facilities for providers of electronic communications networks. In particular, "[c]ompetent authorities shall be able to impose the sharing of such facilities or property, including land, buildings, entries to buildings, building wiring, masts, antennae, towers and other supporting constructions, ducts, conduits, manholes, cabinets or measures facilitating the co-ordination of public works. Where necessary, national regulatory authorities shall provide rules for apportioning the costs of facility or property sharing and of civil works co-ordination." Interestingly, in the last sentence of the cited paragraph, the EECC refers to the role of NRAs in determining charges for infrastructure sharing - thus creating room for regulatory gaming and impacts market arrangements. Furthermore, co-existing specifications in Art. 3 of the cost reduction directive (European Commission, 2014b) create some legal uncertainties with respect to the scope and application of symmetric access regulations. Art. 59 further standardizes access regulations that apply to all firms irrespective of whether they have SMP. Art. 59 (1) lit. a.) and lit. b.) update the pre-existing regulations for ensuring end-to-end connectivity, which can be used to impose obligations on all firms that control access to end-users (usually subscriber network operators) thus requiring them to provide competitors with physical access to the network and/or safeguard the interoperability of their services. The rule in Art. 59 (2), however, is new. This rule stipulates that, regardless of the necessity of safeguarding end-to-end connectivity, NRAs can also impose on firms without SMP the obligation to ensure network access to existing in-house cabling or up to the first concentration or distribution point. According to Art. 59(2), such an access obligation can even be extended on a case-by-case basis to network components beyond the first distribution point. We consider this to be one of the most problematic new rules in the EECC, as access to an infrastructure can now be ordered without any limitations based on either the essential facilities doctrine or the concept of market dominance. Accordingly, such instruments could imply a tremendous broadening of the existing regime of symmetric regulation and thus of the overall regulatory intensity. The latter will exert negative impacts on investment incentives as shown in the theoretical and empirical literature.

A central element of justification for these far-reaching symmetric access obligations would be that such a right of shared use over the existing access infrastructure can lower total deployment costs substantially. Also from theory, if a deregulation regime is not feasible, 
regulation should be at symmetric, i.e. applied to all operators - incumbents, cable operators and other infrastructure operators. This is even more relevant if some firms (such as cable operators) have substantial advantages in terms of costs when it comes to deploying or upgrading broadband access networks. However, the incentivizing effect for investment due to symmetric regulations have to be weighed up against the investment-lowering effect of potentially expanding ex ante regulation to all infrastructure operators and owners and to a broad range of physical access infrastructure elements. While the first effect is dependent on country-specific cost factors (such as the availability of ducts), the latter is determined centrally by the NRA's implementation of symmetric regulation regarding access types and the way regulated access charges are calculated. Envisaged symmetric access regulations might also raise a legal problem insofar as the access to third parties infrastructure without the limitations of the essential facility doctrine (or justified by the end-to-end- connectivity principle) is extended to a wide variety of infrastructure elements without reference to the design of the relevant market. In addition, in practice, symmetric regulations might give rise to a substantial expansion of industry regulation as these regulations are readily available without conducting extensive market definition and SMP analyses (see HSBC, 2016, p. 3). These circumstances and lack of clarity as regards the scope and implementation of symmetric regulations raises serious concerns with respect to investment incentives related to symmetric regulations.

\section{$4 \quad$ Summary and conclusion}

"We need to be connected. Our economy needs it. People need it. And we have to invest in that connectivity now"20. Those were the words of the President of the European Commission - Jean-Claude Juncker - during his 2016 State of the Union address. On the occasion of this general address, the EC published its proposal for a directive establishing the European Electronic Communications Code. The EECC will substantially revise the existing regulatory framework for communications markets with one key aim being the provision of sufficient incentives for infrastructure investments into very high capacity broadband networks.

In this context, based on a review of the most related theoretical and empirical literature of the most relevant regulatory measures - that is, co-investment models as well as different types of access regulation - we provide a critical appraisal of the EECC provisions related to the incentives for infrastructure investments. In the remainder of this concluding section, we will first summarize the main insights from economic research, followed by a discussion of key implications for amendments of the EECC.

\subsection{Main insights from economic research}

Our review of the existing theoretical and empirical literature generally suggests that dynamic efficiency as a main regulatory goal can best be achieved by softer regulatory approaches that enhance NGA investment incentives. Furthermore, positive effects on dynamic efficiency can be expected from a deeper focus on co-investment models and on symmetric forms of

20 'State of the Union 2016: Commission paves the way for more and better internet connectivity for all citizens and businesses', European Commission Press Release, IP/16/3008, 14 September 2016, Strasbourg. 
regulation designed to reduce total deployment costs. While the desire for softer regulatory approaches is primarily based on our review of the empirical evidence - which points to a negative relationship between asymmetric access regulation and NGA investment - the suggested larger role of symmetric forms of regulation is based on the premise that symmetric regulations are expected to create substantial cost synergies and thus higher incentives to invest in new high-speed broadband networks. Vogelsang concludes his survey (2015) in a similar vein: "The emphasis on investment results in a more deregulatory frontier involving softer regulation, cooperative investment, and deregulation or regulatory holidays". A series of such deregulatory approaches has already been implemented by NRAs to varying degrees with the primary intention of increasing profit opportunities and pricing flexibility in order to adapt to changing market conditions. As argued above, softer regulations might also include symmetric regulations and co-investment models.

Co-investment models have already been introduced by some operators after approval by NRAs. Indeed, the idea of joint investment and ownership instead of renting access products represents a promising development in European infrastructure markets. In particular, in grey (or otherwise white) areas, co-investment models - as well as symmetric regulations - seem to be an effective measure for sharing market risks, deployment costs, and market exposure and thus generating additional investment incentives. Whether symmetric regulations and coinvestment models subject to ex-ante approval are in fact suitable instruments for promoting NGA investment depends largely on the exact implementation in individual member states. According to the related academic literature, the more extensive the list of conditions as regards co-investment approvals and the more extensive the definitions of symmetric access products are, the smaller the investment-promoting effect.

Residual asymmetric types of access regulation are based on the dominant market positions of firms (SMP) on the relevant market. Consequently, when addressing the transition to new communications infrastructures and services, it is important to highlight the significance of the preceding analysis stage of market definition. Besides defining product/service markets, particular importance should be attached to a methodically sound definition of geographic markets in terms of the considerable variation in competition conditions between (sub-)urban and rural areas in most countries. If no sufficient substitution patterns are identified which define a common market, one still has to consider the pressure from competition factors (or imperfect substitutes) which are outside the relevant and regulated market; naturally, the stronger the competition-safeguarding functions related to those factors (and products), the stronger the case for favoring deregulation steps (Briglauer and Vogelsang, 2017).

\subsection{Implications for amendments of the EECC}

In light of the insights provided by the economic research just summarized, it is fair to say that although the EECC's proposed measures go into the right direction, they still also contain substantial improvement potential. In particular the following measures to foster NGA investment certainly represent a positive development and are largely in line with the main conclusions and recommendations of this study: i) measures to provide more pricing flexibility to regulated firms; ii) enhancing the role of co-investment models; iii) intensive interventions in terms of asymmetric access regulations only as a ultima ratio policy in case 
all other regulatory policies are deemed insufficient; iv) providing for deregulatory policies in the case of sufficient competitive safeguards; v) measures to reduce regulatory uncertainties such as extending the regulation period; vi) measures to ensure equal baseline conditions for all market participants.

In the following, we summarize major adjustment requirements for the EECC:

First, while the obligation to co-invest as an alternative to access may stimulate investment, the EECC's regulations for co-investment models still contain a considerable regulatory component, with the result that such co-investment models differ substantially from pure voluntary market solutions and their associated ex-ante investment incentives. However, coinvestment models will only induce additional infrastructure investment if the regulatory conditions, which are foreseen ex ante by co-investing parties, are not too restrictive in terms of accruing future investment rewards and in view of the actual extent of risk-sharing and cost reduction.

Sharing risks as regards future demand and market exposure, capital formation in case of capital market imperfections and the primacy of voluntary agreements are the dominant features of effective co-investment models. The risk sharing effect increases the longer participating parties have to co-operate, the more commercially negotiated terms prevail and the lower the scope of regulatory gaming. The organizational mode in which firms cooperate should not be subject to certain ex-ante restrictions. In case of co-investment with obligatory open access, entrants enjoy a cream-skimming option that is exercised when market outcomes are good, whereas the network investor bears all the downside risk. Adding an access obligation on top of co-investment thus reduces the incumbent's profit and therefore total coverage is lower in this regime than under pure co-investment. Ensuring the possibility of entry to late entrants into a co-investment agreement may be viewed as a way to limit the risk of ex post collusion. However, antitrust authorities already have all instruments to address those problems without the need to strength regulatory obligations. Moreover, the granted option for late entrants to join the co-investment, paying an access fee that includes a dynamic risk premium, requires NRAs to precisely assess investment risks and calculate an adequate risk premium for any point in time when a new entrant may join the co-investment. In both theory and practice, this is an extremely difficult and complex task.

Second, although the EECC's proposed regulations on symmetric access obligations are supposed to allow operators to withdraw from more restrictive asymmetric access obligations - and thus to reduce the overall intensity of regulation - the proposed symmetric access regulations actually entail the potential to significantly expand the current regulations to a large number of operators and access infrastructure elements. Moreover, symmetric regulation might de facto give rise to a substantial extension of regulation, as they are readily available to NRAs without the need to conduct extensive market definition and SMP analyses. These circumstances and lack of clarity with respect to the scope (which network elements?) and implementation (which cost-standards?) of symmetric regulations raises serious concerns for the creation of sufficient investment incentives. Of similar concern is the EECC's aim to extend asymmetric access regulations to infrastructure elements outside the scope of the relevant market concept. Residual asymmetric access regulation should be rather imposed in 
cases of persistent monopoly-like bottleneck market structures to safeguard competition. As the traditional interpretation of the essential facility doctrine and the interpretation of market dominance in the EU framework differ, there remains the question of an economic justification for the differentiation between two and three infrastructures within black areas. According to a strict interpretation of the essential facility doctrine, access regulation is limited to white and grey areas. The concept of dominance also opens up the possibility of SMP access regulation in black areas with two or three independent infrastructures in place. Briglauer and Vogelsang (2017) base their conceptual analysis for orienting regulatory policies on the distinction between black, grey and white geographic areas. The authors suggest soft or no regulation - depending on competitive safeguarding functions, the institutional strength of competition and law and whether collusion is expected - in case of duopoly infrastructure, but no regulation in case of oligopoly infrastructure with three or more independent network operators.

According to our analysis of the proposed measures in the EECC we contend that the important goal of encouraging NGA infrastructure investments appears in danger, especially if the expected substantial implementation challenges - in combination with a high degree of complexity of the envisaged measures - are taken into account. 


\section{References}

Bacache, M., Bourreau, M., and Gaudin, G. (2014), Dynamic entry and investment in new infrastructures: Empirical evidence from the fixed broadband industry, Review of Industrial Organization, 44(2), 179-209.

Balmer, R. (2013), Geographic Regulation and Cooperative Investment in Next Generation Broadband Networks: A Review of Recent Literature and Practical Cases, Paper No. 54080. MPRA.

Bauer, J. M. (2010), Regulation, public policy, and investment in communications infrastructure. Telecommunications Policy, 34(1), 65-79.

Bouckaert, J., van Dijk, T., and Verboven, F. (2010), Access Regulation, Competition, and Broadband Adoption: An International Study, Telecommunications Policy, 34, 661-671.

Bourreau, M., Doğan, P., and Manant, M. (2010), A critical review of the "ladder of investment" approach, Telecommunications Policy, 34(11), 683-696.

Bourreau, M., Cambini, C., and Dogan, P. (2012), Access Pricing, Competition, and Incentives to Migrate From "Old" to "New" Technology, International Journal of Industrial Organization, 30, 713-723.

Bourreau, M., Cambini, C., and Dogan, P. (2014), Access regulation and the transition from copper to fiber networks in telecoms, Journal of Regulatory Economics, 45(3), 233-258.

Bourreau, M., Cambini, C., and Hoernig, S. (2016), Cooperative Investment, Access, and Uncertainty, available at: https://papers.ssrn.com/sol3/papers.cfm?abstract_id=2879319.

Bourreau, M., Grzybowski, L. and Hasbi, M. (2017), Unbundling the Incumbent and Entry into Fiber: Evidence from France, unpublished Working Paper, Paris.

Briglauer, W. (2014), The impact of regulation and competition on the adoption of fiberbased broadband services: recent evidence from the European Union member states, Journal of Regulatory Economics, 46(1), 51-79.

Briglauer, W. (2015), How EU sector-specific regulations and competition affect migration from old to new communications infrastructure: recent evidence from EU27 member states, Journal of Regulatory Economics, 48(2), 194-217.

Briglauer, W., Ecker, G., and Gugler, K. (2013), The impact of infrastructure and servicebased competition on the deployment of next generation access networks: Recent evidence from the European member states, Information Economics and Policy, 25(3), 142-153.

Briglauer, W., Frübing, S., and Vogelsang, I. (2015), The impact of alternative public policies on the deployment of new communications infrastructure - A survey, Review of Network Economics, 13(3), 227-270.

Briglauer, W., and Cambini, C. (2016), Promoting Consumer Migration to New Communications Technology: Does Regulation Affect the Digital Gap?, available at: https://papers.ssrn.com/sol3/papers.cfm?abstract_id=2851337. 
Briglauer, W., and Cambini, C. (2017), The Role of Regulation in Incentivizing Investment in New Communications Infrastructure, report prepared for Deutsche Telekom AG, available at:

$\mathrm{ftp} / / / \mathrm{ftp} . z e w . d e / p u b /$ zewdocs/gutachten/BriglauerCambiniDeutscheTelekomApril2017.pdf.

Briglauer, W. and Vogelsang, I. (2017), A Regulatory Roadmap to Incentivize Investment in New High-Speed Broadband Networks, DigiWorld Economic Journal, 106, 143-160.

Briglauer, W, Cambini, C. and Grajek, M. (2017), Regulation and Investment in European High-Speed Broadband Infrastructure, ESMT Working Paper 17, Berlin.

Cambini, C., and Jiang, Y. (2009), Broadband Investment and Regulation: A Literature Review, Telecommunications Policy, 33(10), 559-574.

Cambini, C., and Silvestri, V. (2012), Technology Investment and Alternative Regulatory Regimes with Demand Uncertainty, Information Economics and Policy, 24, 212-230.

Cambini, C., and Silvestri, V. (2013), Investment Sharing in Broadband Networks, Telecommunications Policy, 37, 861-878.

Cave, M., and Feasey, R. (2017), Policy towards Competition in High-Speed Broadband in Europe, in an Age of Vertical and Horizontal Integration and Oligopolies, Project report, Centre on Regulation in Europe.

Cave, M. (2006), Encouraging infrastructure competition via the ladder of investment, Telecommunications Policy, 30(3), 223-237.

Cave, M., and Vogelsang, I. (2003), How access pricing and entry interact, Telecommunications Policy, 27(10), 717-727.

Cave, M., Majumdar, S., Valletti, T., Vogelsang, I., and Rood, H. (2001), The relationship between access pricing and infrastructure competition, Report to OPTA and DG Telecommunications and Post. Brunel University.

Crandall, R. W., Eisenach, J. A., and Ingraham, A. T. (2013), The long-run effects of copperloop unbundling and the implications for fiber, Telecommunications Policy, 37(4), 262281.

Credit Suisse (2016), EU Telecoms Review, 13. January, Europe, Equity Research.

European Commission (2002), Directive 2002/21/EC of The European Parliament and the Council of 7 March 2002 on a common regulatory framework for electronic communications networks and services (Framework Directive), Brussels.

European Commission (2010), Commission Recommendation 2010/572/EU of 20 September 2010 on Regulated Access to Next Generation Access Networks (NGA), Brussels.

European Commission (2013a), Commission Recommendation of 11 September 2013 consistent non-discrimination obligations and costing methodologies to promote competition and enhance the broadband investment environment. C(2013) 5761 final, Brussels.

European Commission (2013b), EU Guidelines for the application of State aid rules in relation to the rapid deployment of broadband networks (2013/C 25/01), Brussels. 
European Commission (2014a), Commission Staff Working Document. Explanatory Note Accompanying the document Commission Recommendation on relevant product and service markets within the electronic communications sector susceptible to ex ante regulation in accordance with Directive 2002/21/EC of the European Parliament and of the Council on a common regulatory framework for electronic communications networks and services. 9.10.2014 SWD(2014) 298, Brussels.

European Commission (2014b), Directive 2014/61/EU on measures to reduce the cost of deploying high-speed electronic communications networks, 15 May 2014, Brussels.

European Commission (2016a), Connectivity for a Competitive Digital Single Market Towards a European Gigabit Society, COM(2016)587 final, Brussels.

European Commission (2016b), Proposal for a Directive of the European Parliament and of the Council establishing the European Electronic Communications Code (Recast), COM/2016/0590 final - 2016/0288 (COD), Brussels.

FTTH Council Europe (2012), FTTH Business Guide, available at: http://www.ftthcouncil.eu.

Grajek, M., and Röller, L.H. (2012), Regulation and Investment in Network Industries: Evidence from European Telecoms, Journal of Law and Economics, 55, 189-216.

Hausman, J. A., and Taylor, W. E. (2013), Telecommunication in the US: from regulation to competition (almost), Review of Industrial Organization, 42(2), 203-230.

HSBC Global Research (2016), European Telecoms - What's in Frame for the EC Telecoms Framework Review, available at: www.research.hsbc.com.

Inderst, R., and Peitz, M. (2012a), Network investment, access and competition, Telecommunications Policy, 36, 407-418.

Inderst, R., and Peitz, M. (2012b), Market asymmetries and investments in Next Generation Access Networks, Review of Network Economics, 11, 1-27.

Inderst, R., and Peitz, M. (2013), Investment under Uncertainty and Regulation of New Access Networks, Information Economics and Policy, 26(3), 28-41.

ITU - International Telecommunications Union (2015), Accelerating Broadband Deployment through Network Sharing and Co-investment, GSR discussion paper.

Jeanjean, F. (2013), Forecasting the fiber penetration according to the copper access regulation, Working Paper, available at: http://ssrn.com/abstract=2209693.

Krämer, J. and Vogelsang, I. (2016), Co-Investment and Tacit Collusion in Regulated Network Industries: Experimental Evidence, Review of Network Economics (forthcoming).

Minamihashi, N. (2012), Natural monopoly and distorted competition: Evidence from unbundling fiber-optic networks, Working paper no. 2012-26, Bank of Canada.

Nett, L., and Stumpf, U. (2011), Symmetrische Regulierung: Möglichkeiten und Grenzen im neuen Rechtsrahmen, WIK-discussion paper Nr. 350, Bad Honnef. 
Nitsche, R. and Wiethaus, L. (2011), Access Regulation and Investment in Next Generation Networks, A Ranking of Regulatory Regimes, International Journal of Industrial Organization, 29(2), 263-272.

Renda, A. (2016), Winners and Losers in the Global Race for Ultra-Fast Broadband: A cautionary tale from Europe. Report prepared for the MacDonald Laurier Institute, available at: http://www.macdonaldlaurier.ca/files/pdf/MLITelecomsPaper08-16webready-V2.pdf.

Samanta, S. K., Martin, R., Guild, K., and Pan, H. (2012), The diffusion of high speed broadband: A cross country analysis, Working Paper, available at: http://ssrn.com/abstract=1997113.

Taga, K., Berguiga, M. and Woo, J. (2009), The Moment of Truth, report, available at: http://www.adlittle.com/downloads/tx_adlreports/ADL_The_Moment_of_Truth_02.pdf.

Vogelsang, I. (2013), The endgame of telecommunications policy? A survey, Review of Economics/Jahrbuch für Wirtschaftswissenschaften, 193-269.

Vogelsang, I. (2015), Will the U.S. and EU telecommunications policies converge? A survey, Economia e Politica Industriale - Journal of Industrial and Business Economics, 42, 117-155.

Vogelsang, I. (2016), The Role of Competition and Regulation in Stimulating Innovation Telecommunications, Telecommunications Policy, forthcoming.

Wallsten, S., and Hausladen, S. (2009), Net neutrality, unbundling, and their effects on international investment in next-generation networks, Review of Network Economics, $8(1)$.

Yoo, C. S. (2014), US vs. European broadband deployment: What do the data say? U of Penn, Institute for Law and Economics Research Paper, 14-35. 